DOI: $10.20535 / 2077-7264.2(72) .2021 .123609$

(ㄱ. Т. Ю. Киричок, д-р техн. н., проф., Н. Л. Талімонова, канд. техн. наук, доц., Т. Є. Клименко, канд. техн. наук, доц., В. А. Баглай, асп., КПІ ім. Ігоря Сікорського,

Е. М. Руденко, д-р техн. наук, проф., Інститут металофізики ім. Г. В. Курдюмова НАН України,

Я. Ю. Талімонов, асп. , А. Є. Новицька, студ., КПІ ім. Ігоря Сікорського, Київ, Україна

\title{
ВПЛИВ ТЕХНОЛОГІЧНИХ РЕЖИМІВ ОБРОБКИ ЛАТУННОЇ ОСНОВИ НА ЯКІСТЬ ФОРМ ІНТАГЛІОДРУКУ
}

Досліджено вплив параметрів та технологічних режимів обробки латуні на якість ії̈ поверхні та адгезію захисного покриття для виготовлення форм інтагліодруку методом прямого лазерного гравіювання.

Ключові слова: інтагліодрук; друкарські форми; пряме лазерне гравіювання; гравійовані штрихи; латунь.

\section{Постановка проблеми}

Для виготовлення форм інтагліодруку можливе застосування декількох технологій. Сучасна технологія полягає у прямому лазерному гравіюванні латунної пластини із подальшим нанесенням покриття нітрид хрому. Цей спосіб виключає ряд додаткових операцій та використання значної кількості шкідливих речовин як під час традиційної технології травлення [1], однак виготовлена у такий спосіб друкарська форма може поступається тиражостійкістю через відшаровування захисного покриття [2]. Тому доцільним є дослідження технології та режимів обробки поверхні латуні перед нанесенням за- хисного покриття, їх вплив на адгезію та міцність поверхні пластини [3].

\section{Мета роботи}

Дослідження впливу параметрів та технологічних режимів обробки латуні на якість її поверхні та адгезію захисного покриття.

\section{Аналіз попередніх досліджень}

Технологічні особливості інтагліодруку привертають увагу багатьох науковців та фахівців, про що свідчить значна кількість патентів та публікацій за даним напрямом. Результати проведеного патентного пошуку дозволили виявити, що найбільш популярним напрямом дослідження 
процесу інтагліодруку є устаткування, яке використовується для його здійснення (понад $28 \%$ від знайдених за тематикою патентів). Також велика кількість патентів присвячена новітнім технологіям виготовлення форм інтагліодруку (22 \%), значна частина 3 них - прямому лазерному гравіюванню форм [4, 5].

В статті [6] описано порівняння декількох технологій виготовлення форм інтагліодруку - технологію прямого лазерного гравіювання та традиційну технологію виготовлення з урахуванням як роздільної здатності, так і оперативності та екологічності виготовлення форм. Виявлено, що технологія прямого лазерного гравіювання дозволяє виготовити друкарську форму значно швидше та без застосування шкідливих для середовища речовин, а мінімальна ширина штриха, який можна відтворити за допомогою такої друкарської форми може становити 10 мкм, що свідчить про високу роздільну здатність.

У той же час, обробка форм лазером і подальше нанесення захисного покриття може призвести до зниження тиражостійкості форм порівняно із традиційними технологіями виготовлення. У попередніх роботах [7] було виділено три основні групи факторів, які впливають на тиражостійкість форм інтагліодруку: параметри процесу гравіювання (спосіб видалення напливів металу в процесі лазерного гравіювання); параметри форми інтагліодруку (спосіб виготовлення, параметри штрихів); параметри процесу вакуумного напилен- ня (температура підкладки, шорсткість пробільних та друкувальних елементів, товщина нітридхромового покриття, режимів травлення підкладки в камері напилення, відсотковий склад газової суміші $\mathrm{Ar}-\mathrm{N}_{2}$ в камері напилення). Тому технологія прямого лазерного гравіювання потребує удосконалення режимів гравіювання та підготовки латунної основи до подальшого нанесення захисного покриття.

\section{Методика проведення досліджень}

Для проведення досліджень було використано модельну латунну форму (латунь марки Л63), яку було запроектовано і виготовлено фахівцями Банкнотномонетного двору Національного банку України із застосуванням системи прямого лазерного гравіювання Jura JSP Direct Laser Engraver. Модельна форма містить вісім ідентичних ділянок (плашок) з набором друкувальних елементів з різною геометрією поперечних профілів [8].

Модельну форму після відповідної процедури очищення було оброблено у плазмі геліконного розряду за допомогою установки для іонно-плазмового формування вуглецевих нанотрубок та інших наноструктур [9, 10]. Час обробки становив 10 та 45 хв; технологічні параметри обробки зразків мали незначну варіацію (табл. 1, де $U_{\text {ст }}-$ напруга, що подавалася на столик-підкладкотримач, $\mathrm{I}_{\text {ст }}$ - іонний струм, $\mathrm{P}$ потужність на зразку, $\mathrm{i}_{\mathrm{cT}}-$ густина іонного струму, $\mathrm{t}$ - час обробки). 
Таблиця 1

Технологічні параметри обробки зразків

\begin{tabular}{|c|c|c|c|c|c|c|}
\hline $\begin{array}{c}\text { № } \\
\text { зраз- } \\
\text { ка }\end{array}$ & $\begin{array}{c}\mathrm{U}_{\text {ст, }} \\
\mathrm{B}\end{array}$ & $\begin{array}{c}\mathrm{I}_{\mathrm{cT}}, \\
\mathrm{MA}\end{array}$ & $\begin{array}{c}\mathrm{P}, \\
\mathrm{BT}\end{array}$ & $\begin{array}{c}\mathrm{i}_{\text {ст, }}, \\
\mathrm{MA} / \mathrm{cm}^{2}\end{array}$ & $\begin{array}{c}\mathrm{T}, \\
\text { хв }\end{array}$ & $\begin{array}{c}\text { Тиск, } \\
\text { мм рт. ст. }\end{array}$ \\
\hline 1 & - & - & - & - & 0 & - \\
\hline 2 & -100 & $100-105$ & $10-10,5$ & 5,52 & 10 & $5 \cdot 10^{-3}$ \\
\hline 3 & -100 & $100-110$ & $10-10,1$ & 5,52 & 45 & $5 \cdot 10^{-3}$ \\
\hline
\end{tabular}

Зразки латуні досліджувались за допомогою електронного мікроскопа MIRA 3 TESCAN як до обробки поверхні зразків, так і після неї. Елементний аналіз здійснювався за допомогою енергодисперсійного спектрометра Oxford instruments X-max $80 \mathrm{~mm}^{2}$.

На три види зразків (необроблені, оброблені протягом 10 і 45 хв відповідно) було напилено модельне захисне покриття AIN (нітрид алюмінію) за допомогою іонно-дугового прискорювача та проведено дослідження адгезії отриманого покриття за допомогою механічного адгезиметра відривного типу Novotest АЦ-1 [11].

\section{Результати проведених досліджень}

Мікроскопічні дослідження зразків дозволили виявити, що у результаті обробки поверхні пластини плазмою геліконного розряду спостерігаються зміни як зовнішнього виду поверхні, так і її елементарного складу (рис. 1, табл. 2). В результаті аналізу елементарного складу поверхні виявлено, що збільшення часу обробки призводило до збільшення на поверхні частки Си з одночасним зменшенням Zn і O.

На рис. 2 і 3 представлено зображення ділянки лазерного гравіювання на поверхні латунної пластини до та після обробки в геліконному розряді протягом

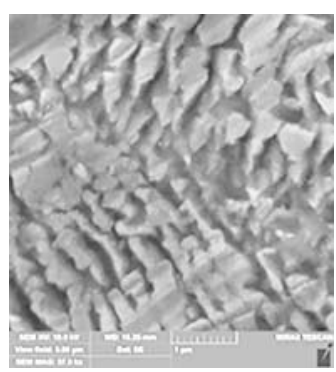

a

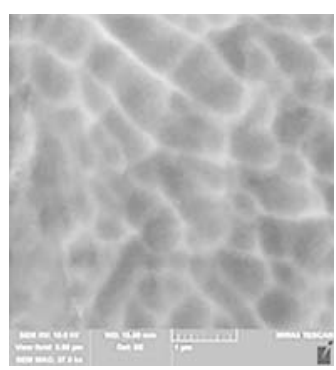

б

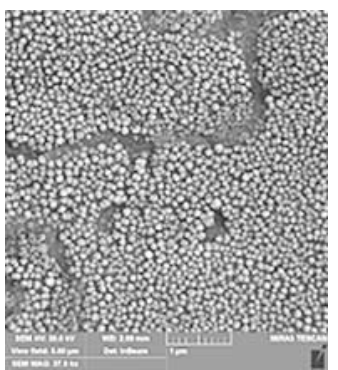

Рис. 1. Мікроскопічні зображення поверхні латуні (5×5 мкм): а - без обробки; б - обробка протягом 10 хв, в - обробка протягом 45 хв 


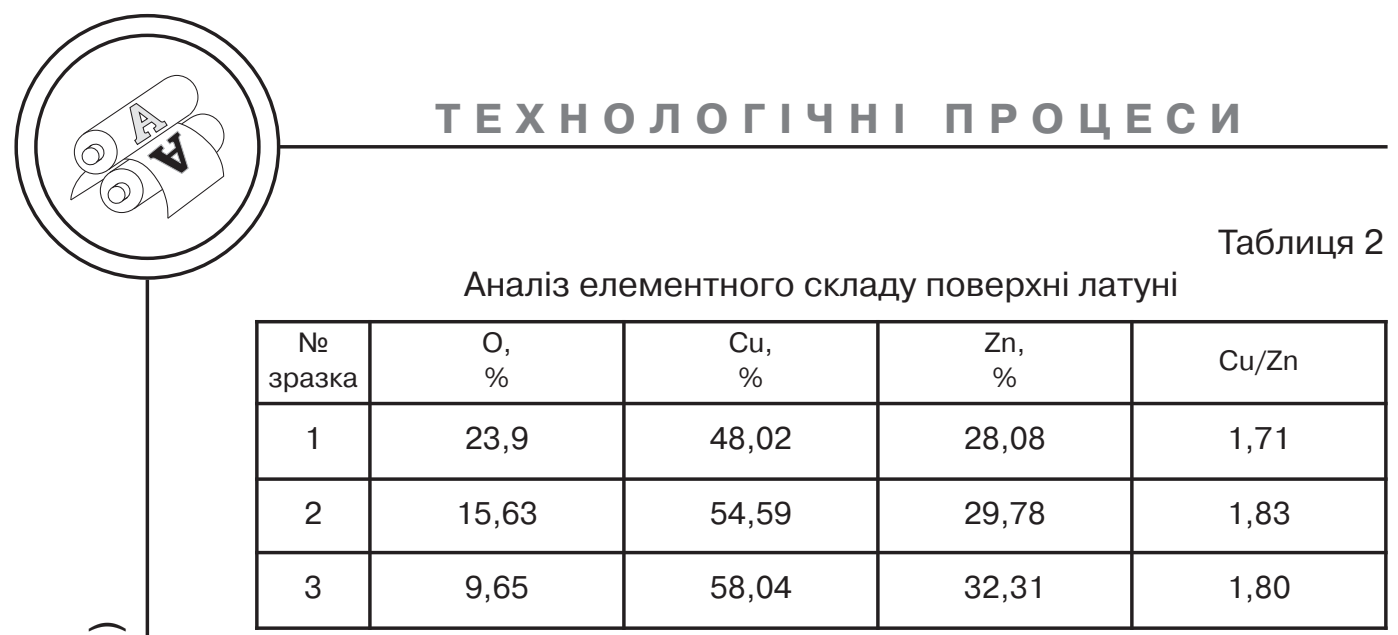

45 хв. Спостерігається зміна структури поверхні, що супроводжується згладжуванням грубого рельєфу, та може сприяти підвищенню адгезії захисного покриття.

Дослідження адгезії модельного покриття AIN дозволило виявити, що найвищий рівень адгезії спостерігається на поверхні латуні, що піддавалася обробці протягом 45 хв, а найменший на необробленій поверхні. Відрив тестового елементу на необробленому зразку відбувся при зусиллі 2,2 МПа, на зразку, що піддавався обробці протягом 10 хв $8 \mathrm{MПа,} \mathrm{на} \mathrm{зразку,} \mathrm{що} \mathrm{піддавався}$ обробці протягом 45 хв - 9,8 МПа.

Аналізуючи отримані результати можна дійти висновку, що у зразків, які оброблялись в плазмі геліконного розряду, показ- ник адгезії збільшився, і це говорить про те, що обробка латуні $€$ доцільною задля покращення в подальшому адгезії із захисним покриттям.

\section{Висновки}

Дослідження впливу параметрів та технологічних режимів обробки латуні на якість її поверхні та адгезію захисного покриття для виготовлення форм інтагліодруку методом прямого лазерного гравіювання дозволили виявити, що у зразків, які оброблялись в плазмі геліконного розряду, показник адгезії збільшився, що свідчить про доцільність обробки латуні задля покращення в подальшому адгезії із захисним покриттям.
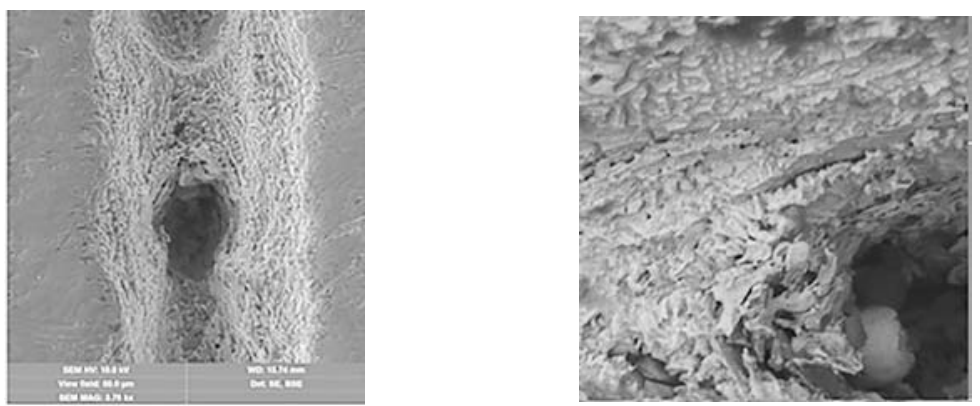

Рис. 2. Ділянка необробленої латунної пластини із штрихом, нанесеним методом прямого лазерного гравіювання (50×50 мкм; 5×5 мкм) 

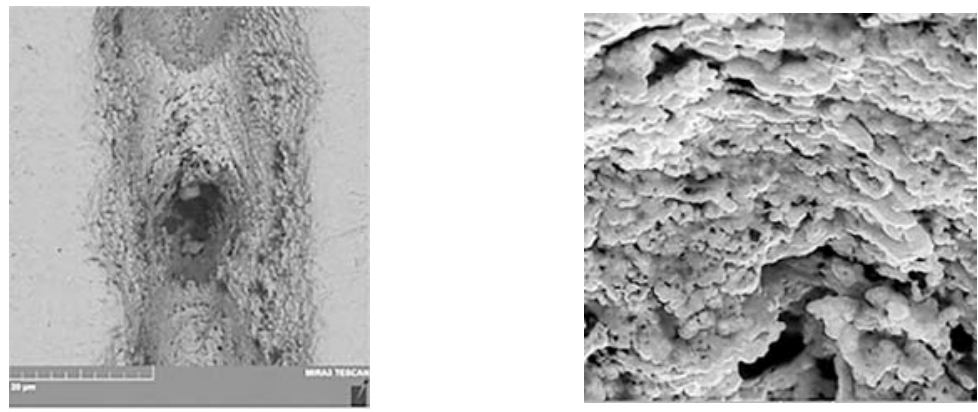

Рис. 3. Ділянка обробленої латунної пластини із штрихом, нанесеним методом прямого лазерного гравіювання (50×50 мкм; 5×5 мкм)

\section{Список використаної літератури}

1. Kyrychok T. The influence of pressure during intaglio printing on banknotes durability / Slegio itaka banknotu patvarumui spausdinant giliaspaude / T. Kyrychok, P. Kyrychok, S. Havenko, E. Kibirkštis, V. Miliūnas // Mechanika, vol. 20, no. 3, 2014, p. 327-331.

2. Grimsley M. Automated inspection of intaglio plate measurement for U. S. currency / Max Grimsley, James E. Hess, Mark Poulsen, Ken Rankin, David Curtis and Donald Bayer // Proc. SPIE 4677, Optical Security and Counterfeit Deterrence Techniques IV, (19 April 2002); https://doi.org/10.1117/12.462735.

3. Kyrychok T. 3D light interferometry investigation of ink layer formation during intaglio printing / T. Kyrychok, O. Korotenko // Proc. SPIE 11369, Fourteenth International Conference on Correlation Optics, 1136910 (6 February 2020); https://doi.org/10.1117/12.2553475.

4. Баглай В. А. Патентування інформації про технологічний процес інтагліодруку / В. А. Баглай // Квалілогія книги: матеріали IV Міжнародної науково-практичної інтернет-конференції студентів, магістрантів та аспірантів / Л.: УАД, 2021 (Львів 25 лютого 2021 р.). С. 206-207.

5. Киричок Т. Ю. Зносостійкість банкнотної продукції: монографія / Т. Ю. Киричок. К.: НТУУ «КПІ», 2014. 308 с.

6. Deinhammer H. Direct laser engraving of intaglio printing plates / Harald Deinhammer, Franz Loos, Daniel Schwarzbach, Peter Fajmann // Proc. SPIE 5310, Optical Security and Counterfeit Deterrence Techniques. Vol. 3, June 2004. P. 184-193; doi:10.1117/12.526899.

7. Киричок Т. Ю. Система формування тиражостійкості форм інтагліодруку / Т. Ю. Киричок, В. А. Баглай // Технологія і техніка друкарства. 2019. Вип. 3(65). C. 15-24. DOI: https://doi.org/10.20535/2077-7264.3(65).2019. 196565.

8. Киричок Т. Ю. Методика автоматизованого оцінювання якості технологічної операції прямого лазерного гравіювання форм інтагліодруку [Електронний ресурс] / Т. Ю. Киричок, В. А. Баглай, А. А. Безпалий, П. Г. Регіда // Технологія і техніка друкарства. 2019. Вип. 4. С. 31-41. DOI: https://doi.org/ 10.20535/2077-7264.4(66).2019.208868.

9. Руденко Е. М. Установка для прецизійного іонно-плазмового формування вуглецевих нанотрубок / Е. М. Руденко, І.В.Короташ, В.Ф.Семенюк, К. П. Шамрай // Наука та інновації. 2009. Т. 5, № 5. С. 5-8. 
10. E. M. Rudenko, V. Ye. Panarin, P. O. Kyrychok, M. Ye. Svavilnyi, I. V. Korotash, O. O. Palyukh, D. Yu. Polotskyi, and R. L. Trishchuk. Nitriding in a Helicon Discharge as a Promising Technique for Changing the Surface Properties of Steel Parts // Usp. Fiz. Met., 20, No. 3: 485-501 (2019); doi: 10.15407/ufm.20.03.485.

11. ДСТУ ISO 4624:2019 Фарби та лаки. Визначення адгезії методом відриву (ISO 4624:2016, IDT).

\section{References}

1. Kyrychok, T., Kyrychok, P., Havenko, S., Kibirkštis, E., \& Miliūnas, V. (2014). The influence of pressure during intaglio printing on banknotes durability / Slegio itaka banknotu patvarumui spausdinant giliaspaude. Mechanika, vol. 20, no. 3, 327-331 [in English].

2. Grimsley, M., Hess, J. E., Poulsen, M., Rankin, K., Curtis, D., and Bayer, D. (2002). Automated inspection of intaglio plate measurement for U. S. currency. Proc. SPIE 4677, Optical Security and Counterfeit Deterrence Techniques IV, (19 April). https://doi.org/10.1117/12.462735 [in English].

3. Kyrychok, T., \& Korotenko, O. (2020). 3D light interferometry investigation of ink layer formation during intaglio printing. Proc. SPIE 11369, Fourteenth International Conference on Correlation Optics, 1136910 (6 February). https://doi.org/10.1117/12.2553475 [in English].

4. Bahlai, V. A. (2021). Patentuvannia informatsii pro tekhnolohichnyi protses intahliodruku [Patenting Information about the Technological Process of Intaglio Printing]. Kvalilohiia knyhy (25 February), 206-207 [in Ukrainian].

5. Kyrychok, T. Yu. (2014). Znosostiikist banknotnoi produktsii [Wear Resistance of Banknote Products]. Kyiv: NTUU 'KPI', 308 p. [in Ukrainian].

6. Deinhammer, H., Loos, F., Schwarzbach, D., \& Fajmann, P. (2004). Direct laser engraving of intaglio printing plates. Proc. SPIE 5310, Optical Security and Counterfeit Deterrence Techniques. Vol. 3, 184-193. doi:10.1117/12.526899 [in English].

7. Kyrychok, T. Yu., \& Bahlai, V. A. (2019). Systema formuvannia tyrazhostiikosti form intahliodruku [System of Intaglio Plate Run-Length Creation]. Tekhnolohiia i tekhnika drukarstva, 3(65), 15-24. DOI: https://doi.org/ 10.20535/2077-7264.3(65).2019.196565 [in Ukrainian].

8. Kyrychok, T. Yu., Bahlai, V. A., Bezpalyi, A. A., \& Rehida, P. H. (2019). Metodyka avtomatyzovanoho otsiniuvannia yakosti tekhnolohichnoi operatsii priamoho lazernoho hraviiuvannia form intahliodruku [Method of Automated Quality Assessment for Technological Operation of Direct Laser Engraving of Intaglio Printing Plates]. Tekhnolohiia i tekhnika drukarstva, 4, 31-41. DOI: https://doi.org/10.20535/2077-7264.4(66).2019.208868 [in Ukrainian].

9. Rudenko, E. M., Korotash, I. V., Semeniuk, V. F., \& Shamrai, K. P. (2009). Ustanovka dlia pretsyziinoho ionno-plazmovoho formuvannia vuhletsevykh nanotrubok [Installation for Precision Ion-Plasma Formation of Carbon Nanotubes]. Nauka ta innovatsii, Vol. 5, 5, 5-8 [in Ukrainian].

10. Rudenko, E. M., Panarin, V. Ye., Kyrychok, P. O., Svavilnyi, M. Ye., Korotash, I. V., Palyukh, O. O., Polotskyi, D. Yu., \& Trishchuk, R. L. (2019). Nitriding in a Helicon Discharge as a Promising Technique for Changing the Surface Pro-perties of Steel Parts. Usp. Fiz. Met., 20, No. 3: 485-501. doi: 10.15407/ ufm.20.03.485 [in English]. 
11. DSTU ISO 4624:2019 Farby ta laky. Vyznachennia adhezii metodom vidryvu (ISO 4624:2016, IDT). [Inks and Varnishes. Determination of Adhesion by the Method of Separation]. [in Ukrainian].

The influence of parameters and technological modes of brass processing on the quality of its surface and adhesion of the protective coating for the production of intaglio printing

forms by direct laser engraving has been studied.

Analyzing the obtained results, it can be concluded that in the samples treated in the plasma of the helicon discharge, the adhesion index increased, and this suggests that the treatment of brass is appropriate to improve further adhesion with a protective coating.

Keywords: intaglio printing; printing plates; direct laser engraving; engraved strokes; brass. 